\title{
Do human activity and infrastructure disturb domesticated reindeer? The need for the reindeer's perspective
}

\author{
Anna Skarin · Birgitta Åhman
}

Received: 18 October 2013/Revised: 4 March 2014/Accepted: 25 March 2014/Published online: 11 April 2014

(C) The Author(s) 2014. This article is published with open access at Springerlink.com

\begin{abstract}
In recent decades, human-Rangifer (reindeer and caribou) interactions have increasingly been studied from a scientific perspective. Many of the studies have examined Norwegian wild reindeer or caribou in North America. It is often questioned whether results from these studies can be applied to reindeer in managed herds, as these animals have been exposed to domestication and are also more used to humans. In order to examine the domesticated reindeer's reactions to various disturbance sources, we reviewed 18 studies of the effects of human activity and infrastructure on 12 populations of domesticated reindeer and compared these to studies on wild reindeer and caribou; based on this, we discuss the effects of domestication and tameness on reindeer responses to anthropogenic disturbance. We also consider the relevance of spatial and temporal scales and data collection methods when evaluating the results of these studies. The reviewed studies showed that domesticated reindeer exhibit avoidance behaviours up to $12 \mathrm{~km}$ away from infrastructure and sites of human activity and that the area they avoid may shift between seasons and years. Despite a long domestication process, reindeer within Sami reindeer-herding systems exhibit similar patterns of large-scale avoidance of anthropogenic disturbance as wild Rangifer, although the strength of their response may sometimes differ. This is not surprising since current Sami reindeer husbandry represents an extensive form of pastoralism, and the reindeer are not particularly tame. To obtain a true picture of how reindeer use their ranges, it is of fundamental importance to
\end{abstract}

A. Skarin $(\varangle) \cdot$ B. Åhman

Department of Animal Nutrition and Management, Swedish

University of Agricultural Sciences, P.O. Box 7024,

75007 Uppsala, Sweden

e-mail: anna.skarin@slu.se study the response pattern at a spatial and temporal scale that is relevant to the reindeer, whether domesticated or wild.

Keywords Domestication $\cdot$ Rangifer - Disturbance $\cdot$ Zone of avoidance $\cdot$ Regional scale

\section{Introduction}

Reindeer husbandry is a traditional and essential part of the livelihood of Sámi people in Northern Europe and of major importance to the Sámi culture. The reindeer (Rangifer tarandus tarandus) are herded in a pastoral system, where the animals move freely in the landscape during most of the year. One of the major threats for contemporary Sámi reindeer husbandry is habitat loss due to direct or indirect impact from competing land use (Danell 2005; Pape and Loeffler 2012). The UN Environment Programme and European Union have concluded that nearly one-third of the current traditional Sámi reindeer husbandry ranges in Northern Europe are severely affected by or partly inaccessible for reindeer herding due to the presence of infrastructure, industrial development or other human activity (UNEP 2001; Vistnes 2008). The loss of grazing land is accelerating due to the destruction of foraging areas, obstruction of migration routes and disturbance of reindeer (Tyler et al. 2007). This represents a major challenge for the reindeer herders and society in general. As a consequence, the number of court cases relating to industrial developments in reindeer-herding areas has been growing rapidly (Össbo and Lantto 2011).

Rangifer tarandus (reindeer and caribou-hereafter generally referred to as "reindeer") is a migratory species well adapted to making use of the seasonal shifts in the 
arctic and subarctic environment (White et al. 1981). Obstructions caused by human activity and infrastructure are likely to affect reindeer's choice of seasonal ranges (Senft et al. 1987), which typically cover broad geographic extents (Nagy et al. 2011). To understand the consequences of anthropogenic disturbance on reindeer (or other large herbivores), it is thus necessary to study effects over a variety of scales. During recent decades, researchers have identified various human-reindeer interactions, including those with tourism and hunting (e.g. Aastrup 2000; Reimers et al. 2009; Skarin et al. 2010), road traffic, helicopters and aircraft (e.g. Klein 1971; Harrington 2003; Reimers and Colman 2006), infrastructure and industrial development, such as mining, hydropower and, more recently, wind power (e.g. Wolfe et al. 2000; Nellemann et al. 2003; Vistnes 2008; Colman et al. 2012; Panzacchi et al. 2012; Skarin et al. 2013). Most studies reveal a common pattern in relation to both spatial and temporal scales. When reindeer responses to human activity and infrastructure are studied at the regional scale, the results often show that reindeer avoid disturbances several kilometres away, while studies performed at the local scale close to human activity and infrastructure in most cases fail to show any response to the source of the disturbance (Vistnes and Nellemann 2008).

Most research on human-reindeer interactions has involved wild reindeer in Norway and Svalbard or caribou in North America. Consequently, recent reviews (Wolfe et al. 2000; Reimers and Colman 2006; Vistnes and Nellemann 2008) refer mainly to wild reindeer. An early review within this field pointed out that knowledge of domesticated reindeer in Scandinavia could aid in predicting potential problems for caribou in North America (Klein 1971). Nonetheless, it has been questioned whether conclusions from studies on wild reindeer can be applied to herded reindeer, where the animals have been exposed to domestication and may be more or less used to the presence of humans (Reimers and Colman 2006). Wild reindeer derived from domesticated populations have been shown to have a shorter flight distance than fully wild reindeer (Reimers and Svela 2001; Reimers et al. 2012), suggesting differences depending on degree of domestication.

Animals may respond differently depending on their previous experience of disturbance, resulting in habituation or sensitisation, and thereby a changed tolerance level. It should be noted, however, that differences in tolerance are not necessarily an effect of habituation, although they are often misinterpreted as such (Bejder et al. 2009). Although differences in tolerance to human activity can be measured, it is seldom possible to record true habituation or sensitisation processes in human-animal interactions. The processes occur in individual animals and, therefore, have to be recorded over time for the same individual, while studies of human-animal interactions most often focus on general responses at the population level. Nor is habituation always positive for the animal. An animal can respond with increased tolerance to a disturbance if there is a benefit in accepting the disturbance.

In this paper, we review 18 recent studies on the effects of human activity and infrastructure on behaviour and habitat use of domesticated reindeer in 12 populations and discuss the relevance of domestication, life history and scale. The aim is to clarify whether there are any principal differences between domesticated and wild reindeer in their reaction to human disturbance and, thus, to determine the extent to which conclusions based on studies of wild reindeer are applicable to domesticated reindeer in extensive husbandry systems.

\section{Domesticated, semi-domesticated or tame?}

In the scientific literature, there is some confusion over how to classify herded reindeer. Often these reindeer are referred to as "domesticated" or, especially during recent decades, as "semi-domesticated" and sometimes they are referred to as "tame". Within the field of animal breeding, the term semi-domesticated has not been scientifically defined (e.g. Hemmer 1990; Clutton-Brock 2012). However, M. Utsi used it in 1948 and Y. Espmark in 1964, probably through a desire to distinguish the degree of domestication of reindeer compared to other livestock. The term became increasingly common in the literature from the late 1970s. Taming, on the other hand, is a training process through which the animal becomes accustomed to humans; this is unrelated to the genetic selection process associated with domestication. Both wild and domesticated animals can be tamed (Hemmer 1990). Therefore, "tame reindeer" is generally not an accurate term for Fennoscandian reindeer herded in extensive systems. Irrespective of the degree of domestication, different reindeer herds may exhibit different degrees of tameness depending on the intensity of human handling. In this review, we have chosen to use the term domesticated to describe herded reindeer, reasoning that these animals are as domesticated as they need to be for the practical management of the herd.

\section{Behavioural traits, breeding and domestication of reindeer}

Human-reindeer history goes back to the Palaeolithic period (Helskog and Indrelid 2011; Clutton-Brock 2012) and involves hunting of wild reindeer as well as keeping domesticated reindeer for transportation, clothing and food (Bjørklund 2013). Of the seven different subspecies of 
Rangifer tarandus (Banfield 1961), the Eurasian tundra reindeer ( $R$ t. tarandus) is by far the most common ancestor of the domesticated reindeer (Roed et al. 2008). The domestication of reindeer has mainly included breeding for characteristics that make the animals easier to gather and handle, characteristics that also has importance for their reaction towards disturbances.

Selection of individuals that are easy to handle has resulted in a reduction in the animals' aggression and vigilance when in contact with humans (Baskin 1986; Baskin and Hjältén 2001). Nevertheless, reindeer are still at a rather weak stage of domestication and their tolerance to humans cannot be compared with that of cattle, sheep or dogs for example, where the animals' vigilance behaviour has been fundamentally reduced (Hemmer 1990). Typically for most species, the most important step in the domestication is the reduction in the animals' sensitivity to changes in the environment (Price 1999). The latter is linked to keeping the animal in a "safe" environment, with an absence of stimuli that might imply a threat. Domesticated reindeer, on the other hand, are not particularly protected, nor found outside their native habitats. The herder, therefore, has had little reason to breed for characteristics that help the animal to cope with a confined environment. Thus, domesticated reindeer express most traits in relation to their environment in the same way as their wild relatives, and we can expect similar behaviour, regarding for example avoidance of hazards, in both domesticated reindeer and wild reindeer or caribou (Skjenneberg and Slagsvold 1968; Klein 1971).

The reindeer's tendency to stay in tight herds was probably important when humans started to handle reindeer. During the domestication, herders were more likely to have retained individuals that stick with the herd, rather than solitary individuals (Kitti et al. 2006; Zhigunov 1968). The herd behaviour of the domesticated reindeer is, therefore, expected to be even more gregarious than that of wild reindeer and caribou, which can have implications for their sensitivity to human activity and disturbances (Skjenneberg and Slagsvold 1968; Knight and Cole 1995). Tundra-dwelling reindeer exhibit more gregarious behaviour than taiga-dwelling reindeer, probably as a strategy for avoiding predators in the open landscape (Baskin 1986). The difference is also found between the different ecotypes of North American caribou, where barren-ground caribou are more gregarious than the sedentary ecotypes (Bergerud 1988). We can also speculate in that differences in hunting pressure have strengthened the social bonds and increased the gregarious behaviour in Eurasian reindeer more than in caribou. In Eurasia, the reindeer have been exposed to hunting from the Palaeolithic to the present (Helskog and Indrelid 2011), whereas in North America, human hunters have only been present for the last 20-30 thousand years (Goebel et al. 2008).
The historical use of reindeer in Eurasia has changed to different degrees, from simply hunting wild reindeer to intensive herding, where the animals were even milked (Helskog and Indrelid 2011; Bjørklund 2013). This has affected both the degree of domestication and the degree of tameness. Today we can probably find the highest degree of tameness among reindeer herded by nomadic people in eastern Eurasia (Oskal et al. 2009). In the Sami reindeerherding area, covering northern Fennoscandia, reindeer herding is generally extensive. The animals move freely in the landscape for most of the year and are usually less thoroughly managed than they have been during preceding centuries of more intense herding. They are little influenced by the reindeer herders, other than occasional migrations, gatherings and calf markings (Kitti et al. 2006).

\section{Hierarchical scales of selection}

In order to examine reindeer's responses to human activity and infrastructure, it is necessary to examine the world from the perspective of the animal (irrespective of degree of domestication) and not the physical habitat perceived by humans. In studies of animal resource selection, the importance of recognising scaling has been evident for at least four decades (Wiens 1973; Johnson 1980). Thus, we need to identify the spatial and temporal range within which these animals operate (Manning et al. 2004; Mayor et al. 2009). In 1980, Johnson presented a methodological approach for analysing usage in relation to availability in studies of animal resource preference. He suggests that a natural ordering of the selection process should be identified, from selection of the physical or geographical range of a species (first-order selection), to home range selection (second-order selection), usage within that home range (third-order selection), and finally selection of food items (fourth-order selection). A few years later, a theory with a similar approach was presented by Senft et al. (1987), describing how large herbivores forage in ecological hierarchies (Fig. 1). This theory is based on herbivore foraging response patterns, which operate at three main scales (regional, landscape and patch). The scales are defined by rates of foraging processes, with boundaries defined by animal behaviour. Decisions at the largest of these (the regional scale) potentially have the greatest impact on animal survival and performance since they occur infrequently and often constrain the lower level processes (Senft et al. 1987; Rettie and Messier 2000). When studying the effect of human activities and infrastructure, non-interactive factors such as barriers in the landscape, are important and also have a greater impact on habitat selection at higher levels than at lower levels (Senft et al. 1987). Choices at the regional scale or second-order selection for reindeer include 


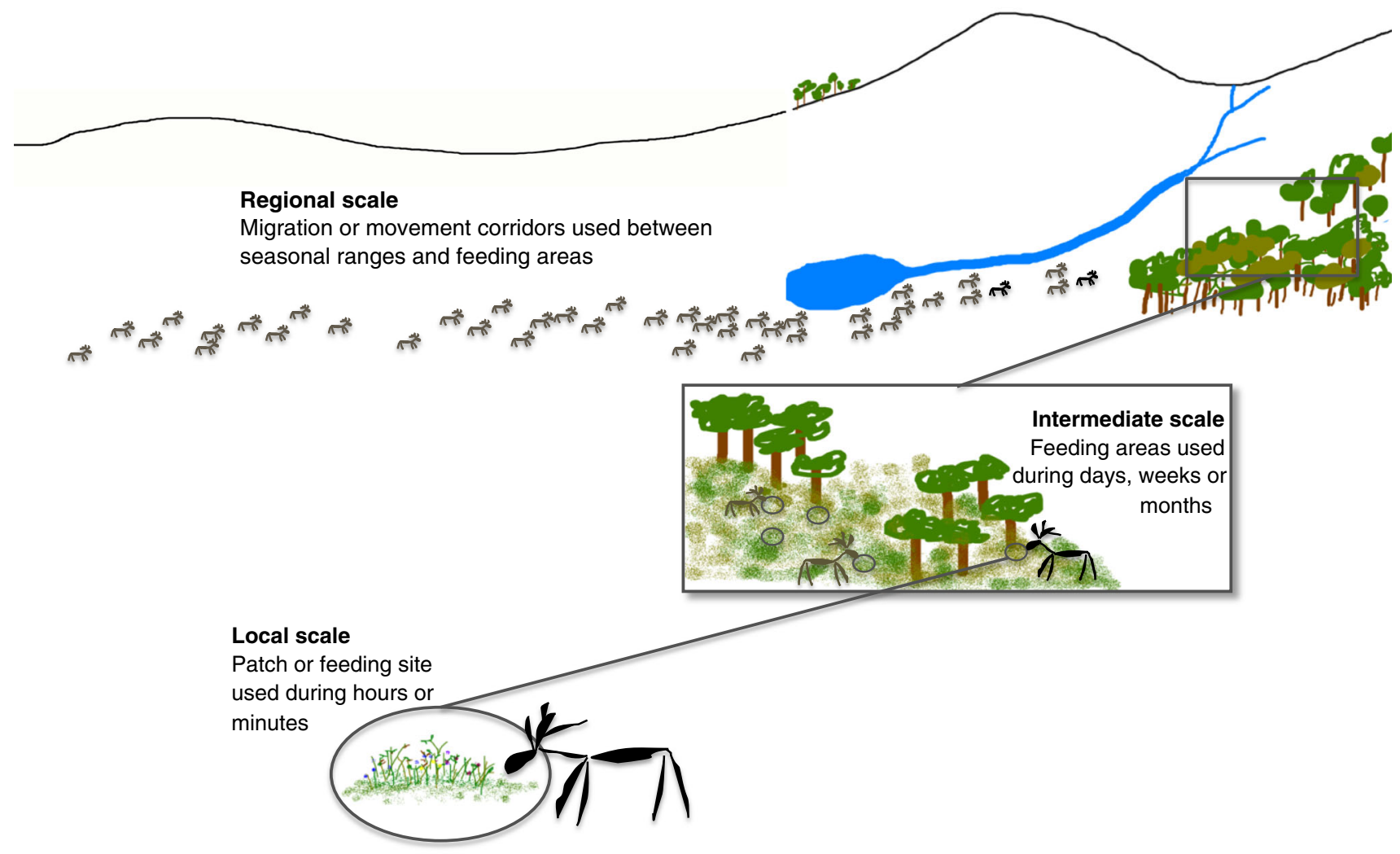

Fig. 1 Scales of selection to define reindeer foraging processes, used in the categorisation of the reviewed studies, illustration modified from Senft et al. (1987)

herd migration between seasonal ranges (Rettie and Messier 2000; Apps et al. 2001; Mayor et al. 2009) or herders moving animals between ranges ( Kitti et al. 2006; Degteva and Nellemann 2013); this represents a kind of a landscapedeparture mechanism rather than landscape selection (Senft et al. 1987). An example of choice at the landscape scale or third-order selection is movement to a new foraging area or patch when foraging conditions become poor (because of weather or previous grazing, for example). Choices at the smallest scale (the patch or fourth-order selection) often relate to the animals' response to vegetation type or plant species (Bailey et al. 1996; Senft et al. 1987) and are thus little affected by non-interactive factors.

The above approach is commonly used when studying large herbivores (domestic as well as wild) as a way to handle the perceptions of the animal at appropriate spatial and temporal scales. Recent studies on animal resource selection use new statistical methods enabling a more dynamic approach, where the full spatial and temporal spectrum of the animals' behaviour can be analysed simultaneously (Leblond et al. 2011; Benhamou and Riotte-Lambert 2012; Wilson et al. 2012). This minimises the risk of missing important behavioural responses at scales that are not explicitly identified in a study.

In their review, Vistnes and Nellemann (2008) identified 85 studies on the effects of human activity and infrastructure on reindeer and concluded that the reaction of reindeer to disturbance differs substantially depending on the scale examined in the study. They found that 32 out of 36 reviewed studies focusing on local (up to $2 \mathrm{~km}$ from a disturbance) and direct effects concluded that the impact on reindeer was small and short-lived. In contrast, when whole populations were examined, and the studies included longer time spans and areas more than $2 \mathrm{~km}$ from the disturbance source, the results showed clear effects of noninteractive factors on the habitat selection by reindeer. Most often (in 44 out of 49 regional-scale studies) the animals avoided a large area around the disturbance.

\section{Disturbance studies involving domesticated reindeer}

Based on the reasoning by Johnson (1980), Senft et al. (1987) and Vistnes and Nellemann (2008), we chose to 
divide the 18 reviewed studies into regional, intermediate and local-scale studies (Fig. 1; Table 1). The criteria for a regional study were that it should include at least a whole seasonal grazing range (second-order selection) and an area further than $2 \mathrm{~km}$ away from the disturbance source. The whole population in question should be included and the observations made from a long-term perspective (months/ years/decades). We defined an intermediate study as one including habitat selection within the landscape scale (e.g. part of a seasonal range or third-order selection) and reindeer habitat selection further than $2 \mathrm{~km}$ away from the disturbance source and having a time perspective of at least months. A study was defined as local if the animals' selection was made within plant communities or patches (fourth-order selection), if it included the recording of short-time periods $(\mathrm{min} / \mathrm{h})$ and involved only part of the reindeer population, usually conducted within a distance of $2 \mathrm{~km}$ of the source of disturbance. A regional study could, therefore, include all scales of selection from region to patch, while an intermediate study could include both the landscape and patch scale of selection.

Two studies by Flydal et al. $(2004,2009)$ were defined as strictly local as they describe observations over a shorttime period, involving a few individuals in enclosures with a wind turbine and two parallel high voltage power lines, respectively. The short-term observations consisted of scan and focal sampling of animals. The scan sampling was undertaken every $10 \mathrm{~min}$, recording the behaviour of all animals in the group. In the focal sampling, the behaviour of a focal animal was observed for 5 min out of every $20 \mathrm{~min}$. All sampling was performed during daylight hours. Two other studies defined as local (Baskin and Hjältén 2001; Nieminen 2013) recorded reindeer flight reactions to direct provocation by a human on foot. Baskin and Hjältén (2001) compared eight reindeer populations of different genetic and phenotypic backgrounds (e.g. from wild to domestic and with different degrees of previous interaction with humans). Nieminen (2013) compared reactions of wild forest reindeer with reactions of domesticated reindeer both in forests and in open tundra.

Four of the reviewed studies (Skarin et al. 2008; Bergmo 2011; Colman et al. 2012, 2013) were defined as studies performed at the intermediate scale. They all describe longterm habitat use and selection of vegetation or habitat quality within part of a seasonal grazing range. Bergmo (2011) counted faecal pellet groups within $5 \mathrm{~km}$ of a $132 \mathrm{kV}$ power line in part of a summer grazing area (not involving the whole herd). The two studies by Colman et al. $(2012,2013)$ use some of the same data from two adjacent peninsulas (around $100 \mathrm{~km}^{2}$ each) that were part of the total summer range $\left(>1,000 \mathrm{~km}^{2}\right)$ of a reindeer herd at Nordkinn in northern Norway. They counted and determined locations of the reindeer in the study area once a month from June to September (Colman et al. 2012, 2013) and performed pellet-group counts (Colman et al. 2013) within $10 \mathrm{~km}$ of a wind power park situated on one of the peninsulas, then compared this to a reference area on the other. The studies were conducted over 5 years and thus had a long-term perspective. Skarin et al. (2008) studied reindeer habitat selection within home ranges (i.e. Johnsons second order of selection or Senfts landscape scale) defined from continuous reindeer GPS location data during two snow-free seasons (May-September). The study evaluated the reindeer's use of home ranges in relation to houses, camp sites and hiking trails, topography and vegetation types in three different grazing areas. This study is somewhere in between the intermediate and regional scale. Whole grazing ranges were studied, and a long-term perspective was used; however, habitat selection was studied within defined home ranges (third-order selection) and the placement of the home range within the landscape (secondorder selection) was not statistically analysed.

Ten of the reviewed studies could be defined as truly regional. Helle and Särkelä (1993) and the follow-up study by Helle et al. (2012) used direct observations of reindeer and pellet-group counts to study changes in reindeer habitat use over time around Saariselkä tourist resort in Finland. Vistnes and Nellemann (2001) used data from observation surveys from a calving range during two consecutive years, evaluating the effect of a cabin area, roads and power lines. Skarin et al. (2004) used pellet-group counts and aerial surveys to register reindeer habitat use in relation to tourism, insect harassment and vegetation types in two summer ranges in the southern part of the Swedish mountains. Skarin et al. (2010) used the same reindeer GPS data as Skarin et al. (2008) above, but in this case to examine reindeer movement rate rather than habitat selection within home ranges. Skarin (2007) used pellet-group counts from the same summer grazing ranges as those studied in Skarin et al. (2008, 2010). Thus, Skarin (2007) and Skarin et al. (2010) compare reindeer habitat selection and activity, respectively, in two Swedish mountain areas with different degrees of tourism impact. Lundqvist (2007) partly used the same GPS data as Skarin et al. $(2008,2010)$ to study fragmentation (barrier effects) caused by hiking trails and roads. Kumpula et al. (2007) and Anttonen et al. (2011) used results from the same GPS-collared reindeer in Finland. Kumpula et al. (2007) evaluated effects of forest harvesting and linear infrastructures on reindeer home range and habitat selection, while Anttonen et al. (2011) focused on the reindeer's reactions to infrastructure and human activity. Skarin et al. (2013) used GPS data and pellet-group counts to study how reindeer were affected during the construction of two small wind power parks in a calving and summer range within a forest area in northern Sweden. 


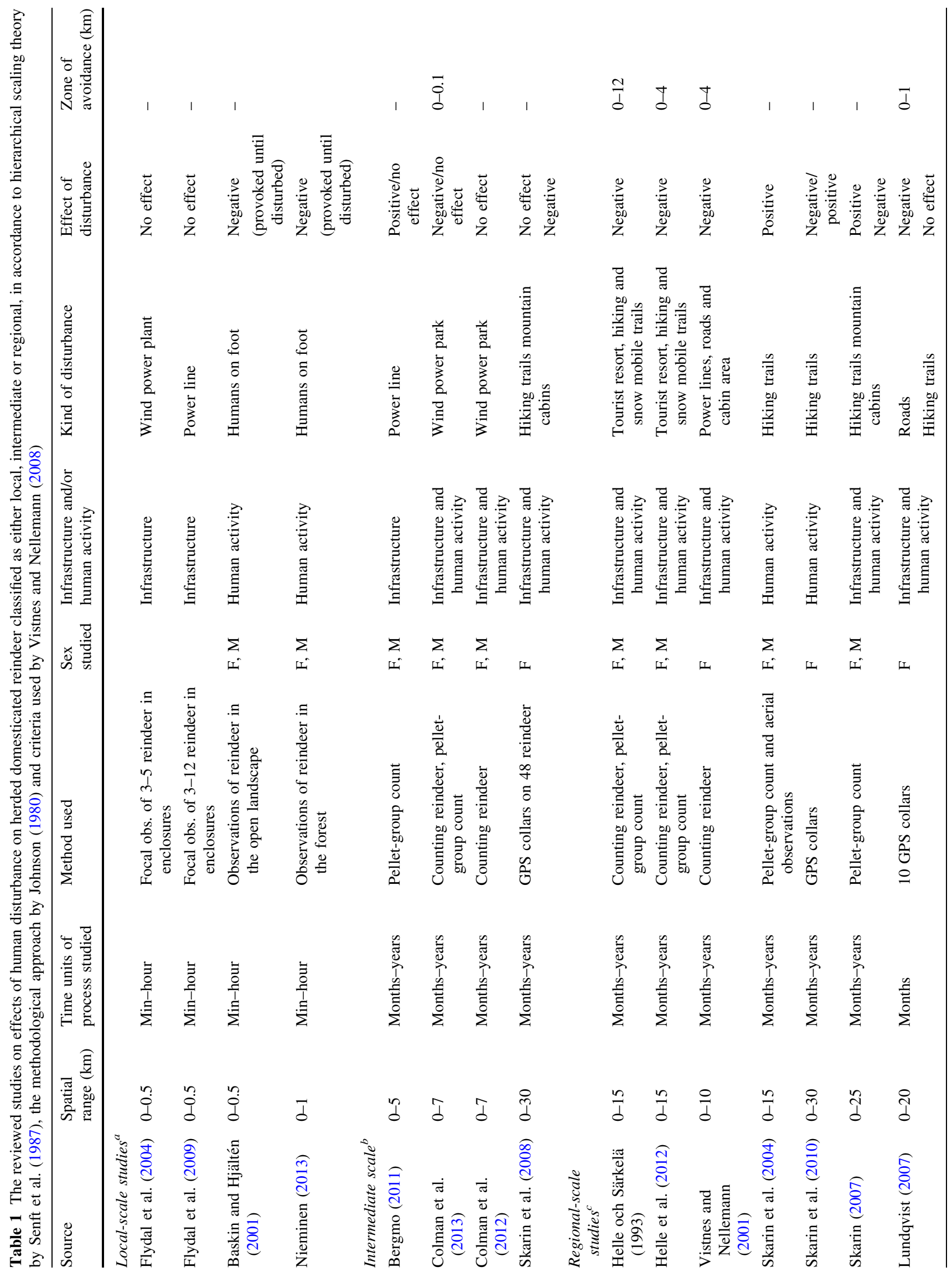




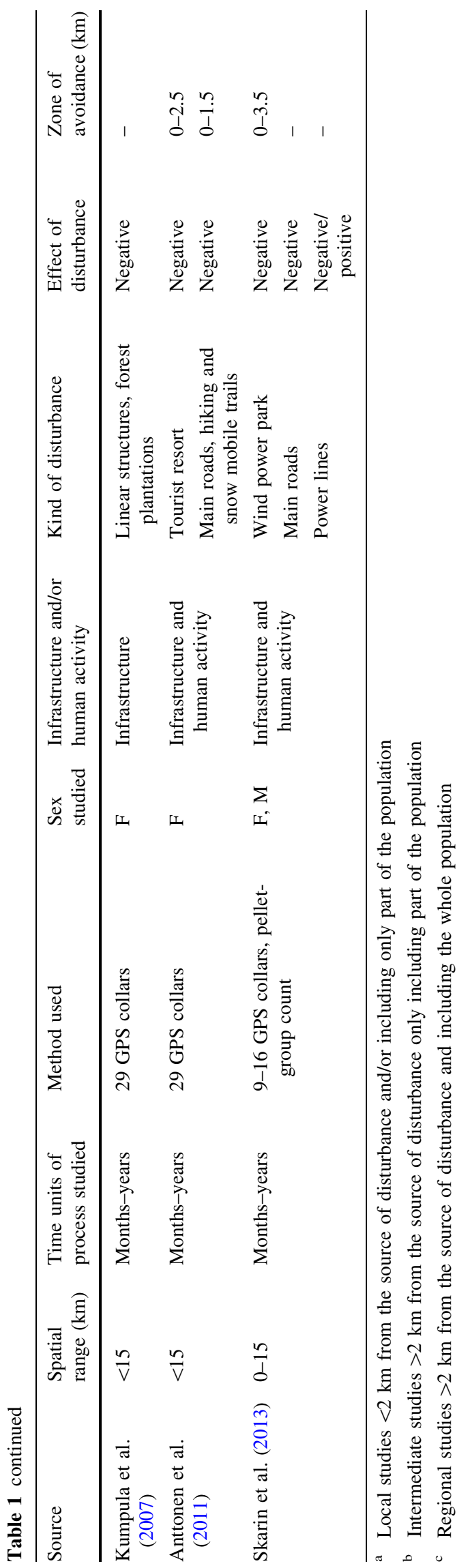

In addition to the studies reviewed over domesticated reindeer, we made an extended search for published studies on wild reindeer and caribou in Web of Science, to compare results on "zone of avoidance" for domesticated and wild reindeer and caribou (Table 2). The search criteria was as follows: "Rangifer" and publication year 2000 to 2013 combined with "anthropogenic disturbance", "zone of influence", "zone of avoidance", or "infrastructure". The obtained publications were then manually selected to find those with information on zone of avoidance from human activity or infrastructure.

\section{Relevance of a large-scale perspective for domesticated reindeer}

Following the classification of Vistnes and Nellemann (2008), we found that all reviewed studies with a regionalscale perspective revealed an impact of human disturbance on reindeer (although in some cases positive), while studies at smaller scales found vague or no effects of the disturbance source investigated. The local-scale studies had the same focus as previous studies involving wild reindeer and measured responses that appeared in animal flight reactions or short-term behavioural changes. As in studies of wild reindeer (e.g. Hanson 1981; Reimers and Svela 2001), few signs of avoidance or disturbance were found for domesticated reindeer at this scale of perception (Flydal et al. 2004, 2009). Baskin and Hjältén (2001) found that domesticated reindeer had a shorter flight distance than wild reindeer, but still they fled from an approaching person. Nieminen (2013) made similar observations and also found that reindeer that were fed by their herders were easier to approach. In many of the local-scale studies, the animals were either restricted to a small area or were individuals that, for some reason, have taken up residence in the neighbourhood of the disturbance source (e.g. Baskin and Hjältén 2001; Reimers and Colman 2006). In the latter case, it is usually unclear if, or how, the studied individuals differ from other reindeer from the same herd, e.g. in how susceptible they are to human activity.

Studies defined as intermediate scale (Skarin et al. 2008; Bergmo 2011; Colman et al. 2012, 2013) may not demonstrate any effects of human activities or infrastructure, at this scale preferred forage types are usually more important (Senft et al. 1987). Skarin et al. (2008) found clear selection of vegetation type, along with a preference for certain altitudes and aspects. Avoidance of cabin areas and solitary houses could, however, be demonstrated during the post-calving period, while no response to hiking trails was found at any time during the summer. Colman et al. (2013) found that roads to the wind power park were avoided by a margin of $500 \mathrm{~m}$ during the year of construction, but not 


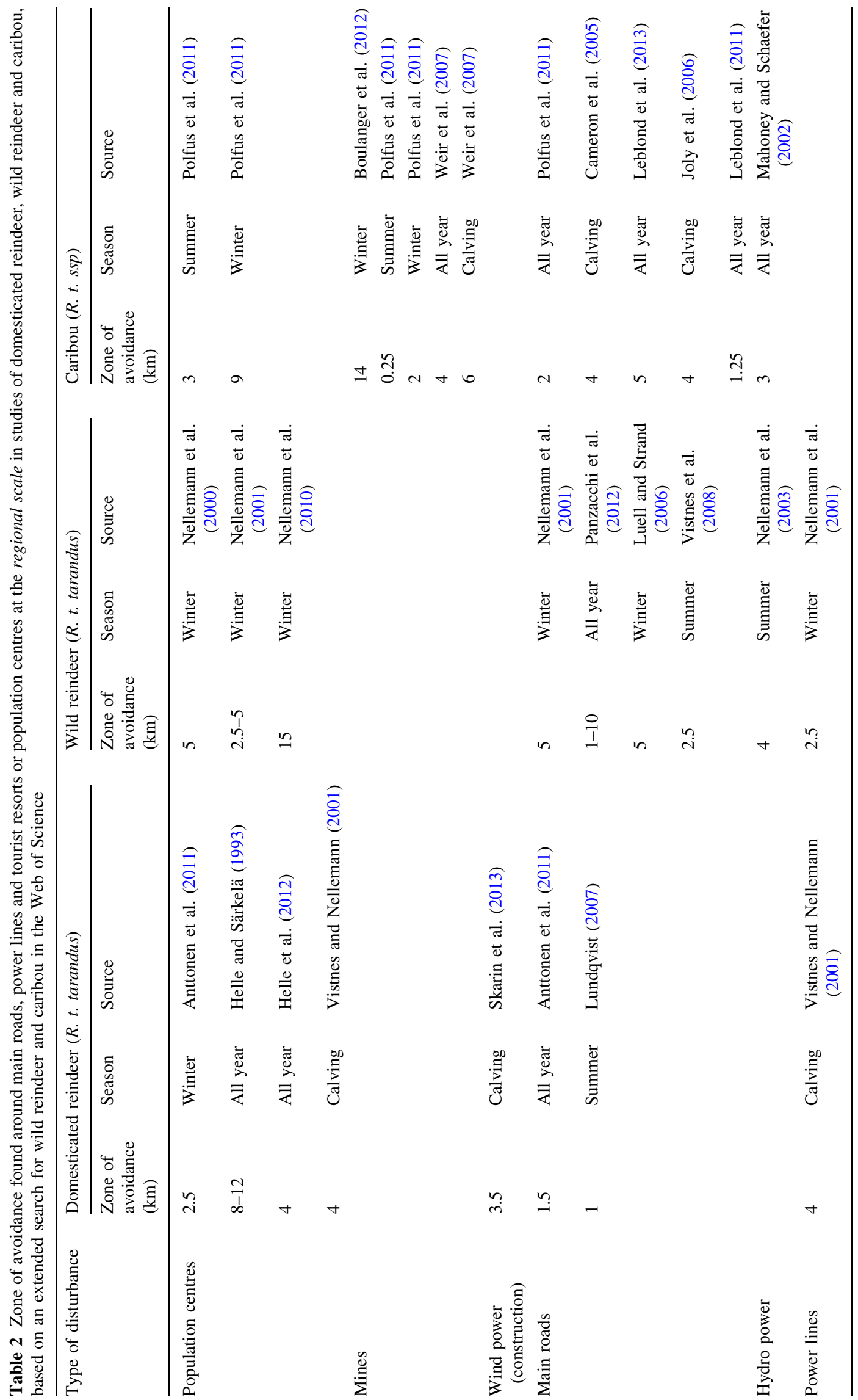


avoided during later years. What they did observe, like Skarin et al. (2008), was a preference for high-quality vegetation types within the study area. The authors point out the limitations of their study, i.e. that it was conducted on a peninsula, giving the reindeer little opportunity to escape the area and that it did not include the range of the whole reindeer herd. Nevertheless, they state that their results stand in contrast with former large-scale studies (Nellemann et al. 2000, 2003; Vistnes and Nellemann 2001; Vistnes et al. 2001, 2004). However, within the hierarchy and considering that the study was undertaken at the (or third-order selection) landscape scale, the limited response to the disturbances studied could, perhaps, be expected. Plausibly, at this scale, the most important factors for habitat selection are vegetation type and habitat quality, which they also showed.

Physical barriers in the landscape may hinder animals from moving between ranges, and the effects of these are probably apparent at the regional scale (Senft et al. 1987; Vistnes and Nellemann 2008). Bergmo (2011) and Colman et al. (2012) studied the effects of barriers in the landscape at the intermediate scale, where effects are probably not evident because the reindeer have already made a selection at the regional scale. In Colman et al. (2012), the reindeer density on the peninsulas studied (4 reindeer $/ \mathrm{km}^{2}$; from Colman et al. 2013) compared to the remaining Nordkinn area $\left(9-10\right.$ reindeer $\left./ \mathrm{km}^{2}\right)$ reveals a substantial difference between the ranges, indicating possible selection before the reindeer enter the study area. Since neither Bergmo (2011) nor Colman et al. (2012) found any effect of barriers, it is possible that there really is none, but because there is no information about reindeer distribution at the regional scale, the results are hard to interpret. Furthermore, it is unclear how the studied reindeer relate to the rest of the herd as regards tolerance to disturbance.

Out of the ten regional-scale studies reviewed, nine showed that human activity and infrastructure had a negative impact on reindeer's choice of grazing range. In some of these, a zone of avoidance around the disturbance, ranging from 1 to $12 \mathrm{~km}$ depending on type of human activity and infrastructure, could be identified and estimated. Main roads were avoided by a distance of 1-1.5 km (Lundqvist 2007; Anttonen et al. 2011), population centres by $2.5 \mathrm{~km}$ (Anttonen et al. 2011) and tourist resorts with hiking and snow mobile trails by up to $8-12 \mathrm{~km}$ (Helle and Särkelä 1993). In the latter area, avoidance declined after actions had been taken to reduce the disturbance, but female reindeer still avoided the closest 4-km zone around the resort (Helle et al. 2012). Skarin (2007) found that reindeer avoided staying close to mountain cabins and lodges during summer, while a preference for hiking trails was reported by both Skarin et al. (2004) and Skarin (2007). In Skarin et al. (2010), the reindeer movement rate increased close to hiking trails (suggesting an aversion effect of trails) in a region with a low density of hiking trails, while the movement rate decreased in a region with a high density of hiking trails (suggesting a higher tolerance to the trails). Note the difference in results between this study and Skarin et al. (2008), where the same data are used, studying reindeer third-order selection, in the latter there is no effect of hiking trails on reindeer habitat selection. Vistnes and Nellemann (2001) observed female reindeer during calving in 2 years and found that the reindeer avoided a cabin area with power lines and roads, as well as a separate power line, by a distance of $4 \mathrm{~km}$. Likewise, Skarin et al. (2013) found that reindeer avoided existing power lines and main roads during the whole snow-free season. Furthermore, previously preferred ranges were avoided when construction of a wind power park started, with animals keeping $3.5 \mathrm{~km}$ away during the calving period. There was also a corresponding increase in the use of adjacent areas that had been used less before the wind power construction.

Anttonen et al. (2011), studying reindeer habitat selection at both the regional and intermediate scale, evaluated selection of home range area and habitat within the home range and found the strongest avoidance of infrastructure and human activity associated with selection of home range area (i.e. regional scale). The avoidance was observed in both winter and summer, although it was stronger in winter. Using the same GPS data, Kumpula et al. (2007) showed that reindeer preferred old-growth forest and avoided linear structures and felled areas in winter, both when selecting home range (second-order selection) and in the (third-order) selection of habitat within their home range. The strong preference for old-growth forest on both scales was explained by high availability of lichens. Comparing regional and intermediate scales of selection reveals stronger responses to human activity and infrastructure at the larger scale. These two studies and the other studies discussed above provide empirical evidence that important effects of human activities and infrastructure may be missed if we do not conduct studies at a regional scale.

GPS data potentially provide data over long time and large scale but usually on few individuals (because of the relatively high costs). Pellet-group counting (faecal density) measures the accumulated use of an area over a defined time period and is a common method to determine long-term habitat use by animals (Skarin 2007). However, pellet-group count data need to be corrected for possible differences in decay rate in different vegetation types (Skarin et al. 2008). This is accounted for in the regionalscale studies reviewed (Helle and Särkelä 1993; Skarin 2007; Helle et al. 2012), while it is missing in the intermediate scale studies (Bergmo 2011; Colman et al. 2012, 2013). 


\section{Infrastructure or human presence?}

Research on domesticated and wild reindeer over the past 15-20 years shows that the most commonly identified response to continuous disturbance or permanent interventions, such as roads, power lines, buildings, pipelines, mines, etc., is that the animals avoid the source of disturbance by a distance of 0.25 to $15 \mathrm{~km}$ at the regional scale (Table 2). Human presence related to infrastructure increases the sensitivity of wild animals to disturbance (Frid and Dill 2002). We could, therefore, expect some differences between wild and domesticated animals in their avoidance distance depending on whether there are humans present or not. This could either be an effect of domestication, making domesticated animals less vigilant in general, and thereby more tolerant towards human activity, or because domesticated animals are more accustomed (tame to some degree) to humans than wild ones and therefore do not show the same level of avoidance of humans. Comparing avoidance distances in studies of domesticated and wild reindeer (Table 2) suggests longer distances when human activity is involved in the disturbance (compare, for example, main roads to population centres). There is, however, no obvious difference related to degree of domestication. The avoidance distance from a tourist resort was about the same for domesticated reindeer (Helle and Särkelä 1993) as for wild reindeer in Norway (Nellemann et al. 2010). However, due to differences in methodology and degree of human activity and infrastructure in the different studies, it is not possible to distinguish whether domesticated reindeer approach sources of disturbance more closely than wild reindeer and caribou.

\section{Effects of nutrition and season}

As pointed out by Bejder et al. (2009), the effects of human disturbance on wildlife are complex and cannot be captured solely by measures of range use or observations of animal behaviour. This is also true for free-ranging reindeer. The full effects are manifested in body condition, survival and reproduction. However, since animal nutrition is affected by a variety of naturally fluctuating factors, weather in particular, the effects of a certain disturbance source on body mass or calving success, for example, are not easily distinguished from naturally occurring effects. Even in experimental set-ups, it is hard to arrange studies in which nutritional conditions could be standardised.

Avoidance of an area with good pasture will evidently result in either increased animal density in alternative areas or use of areas that are otherwise abandoned and presumably of less good quality. Even if reindeer have access to seemingly (to the human eye) high quality pasture, there are large variations in nutritional quality between different plants and plant parts. White (1983) has elegantly illustrated the multiplier effect of the animals' ability to select highly digestible forage. Using an example associated with reindeer grazing, the author demonstrates how a small increase in plant digestibility (14\%), more than doubles the projected body weight gain. High animal density, restricted availability of edible plants or a smaller portion of plants with high nutritive quality will ultimately impair animal nutrition and negatively affect future survival and reproduction.

During periods of nutritional stress, animals will be especially sensitive to disturbance. As described in Vistnes and Nellemann (2001), and Skarin et al. (2008, 2013), the calving period is a time when female reindeer are particularly sensitive to disturbance. The energy demand associated with lactation is high, and the growth of new vegetation has just started (White 1992). Any disturbance that prevents the female from using the available pasture will thus be detrimental. Furthermore, Anttonen et al. (2011) showed that reindeer were more sensitive to human disturbance in late winter compared to summer-autumn and early winter. In late winter, reindeer have usually depleted much of their fat reserve, and at the same time, hard snow and ice crusts may obstruct foraging. Thus, there seems to be an agreement that the calving period and late winter are generally the most sensitive periods for both wild and domesticated reindeer with respect to disturbance.

Adult females will also be more affected by disturbance during times other than calving, since they differ from bulls and juveniles in their reaction to disturbances. While bulls and yearlings graze in separate herds during the summer and more often favour good pasture, females have been shown to prefer an undisturbed environment at the expense of forage quality (Maier et al. 1998; Helle et al. 2012). The difference in response between the sexes has great relevance for reindeer husbandry, where the herd is mostly made up of reproductive females, with young animals and bulls representing only a small proportion (in Sweden, on average $90 \%$ of the reindeer over 1 year of age are females according to data from the Swedish Sami Parliament). This implies that there is a larger proportion of sensitive animals in domesticated populations than in wild populations.

\section{Tolerance and habituation}

Habitation processes are hard to follow and seldom reported (Bejder et al. 2009). The change in tolerance level towards a disturbance is more often reported. However, to date, there is little proof of increased tolerance among wild reindeer at the regional scale (Vistnes and Nellemann 
2008). For example, wild reindeer in Norway were shown to avoid 10 alpine ski resorts during a 20 -year period and did not come back to these areas until ski trails and associated cabins were removed (Nellemann et al. 2010). There was no sign of the reindeer returning to the areas before removal of the cabins and trails, demonstrating that this was a response to the removal and not increased tolerance of their presence. Helle and Särkelä (1993) observed that domesticated reindeer, especially females with calves, avoided the area around a large tourist resort up to a distance of 8-12 km. In 2000, after actions had been taken to direct human utilisation of the area to fewer and better marked routes for hiking and skiing, the female reindeer came closer to the tourist site (Helle et al. 2012), but still avoided the area within $4 \mathrm{~km}$ of the resort. Despite of a doubling of the number of visitors, the actions apparently enabled the reindeer to return, in part, to their original ranges. In this case, the actions implemented apparently had a major effect. However, a possible increase in tolerance towards humans (habituation) could not be excluded. Even though habituation of reindeer to human activities would make the coexistence between modern society and reindeer herding easier in many ways, habituation is not unambiguously "good" (Bejder et al. 2009). If, for example, reindeer are habituated to roads, both reindeer and humans can suffer because of an increase in the number of animal-vehicle accidents.

Clear differences between wild and domesticated reindeer with respect to their tolerance to human presence were found at the local scale by Baskin and Hjältén (2001). They observed that humans on foot came closer to domesticated than to wild reindeer before the animals took flight. They also found that larger groups of reindeer tolerated humans at a closer distance, as did groups with mainly males compared to those with females. The former contradicts our previous reasoning that domesticated reindeer, with stronger social bonds and moving in larger herds, are likely to be more vigilant. However, we would argue that reindeer being approached react in a different way than reindeer approaching an object. When a herd is approaching, the most vigilant animals will decide the behaviour of the herd: when they take flight or choose another route, the rest of the herd will follow (Knight and Cole 1995). This is not the case when a herd is being approached. In this situation, the (false) security of being part of a large herd might make the animals remain in their location as long as possible.

One of the keys to understanding the long-term effect of disturbance is the difference between individuals in regional avoidance discussed above. Even though there are seemingly unaffected animals residing near human interventions, there may also be animals that have withdrawn from the area because of the disturbance. The overall reaction of the herd is based on a continuum of individual tolerance within the population (Knight and Cole 1995; Vistnes and Nellemann 2008; Bejder et al. 2009). Thus, despite the fact that some local short-term studies have found that reindeer may develop increased tolerance to human disturbance over time, it is risky to draw conclusions on how, for example, a permanent industrial expansion may affect animal populations on a larger scale (Bejder et al. 2009).

\section{Conclusion}

Based on our review, we conclude that a large-scale (regional) and long-term (month/year) perspective is necessary to catch the reindeer's perspective related to human activity and infrastructure. At smaller scales, it is not possible to fully detect the possible implications of barriers or obstructions in the terrain that may hinder the animal to escape a disturbance and force it to choose a certain habitat. Looking at the intermediate or local scale will mainly reveal the reindeer's selection of patches, in relation to forage quality, within a home range or an important area. Despite a long domestication, reindeer within Sami reindeer-herding systems exhibit similar patterns of large-scale avoidance of anthropogenic disturbance as wild Rangifer, although the strength of their response may sometimes differ. There may be somewhat shorter avoidance distances among domesticated reindeer, but there is still an upper limit for the amount of disturbance domesticated reindeer will withstand. The largest differences between wild and domesticated reindeer are found in local and short time scale studies. However, at this scale, the overall effects of human disturbance cannot really be evaluated. To obtain a true picture of how reindeer use their ranges, it is of fundamental importance to study the response pattern at a spatial and temporal scale that is relevant to the reindeer, whether domesticated or wild. Moreover, recent analytical methods available can also be used to better grasp the full spatial and temporal spectrum of animal habitat use. For management purposes, quantification of zone of avoidance for domesticated reindeer, and subsequent effects on animal condition and herd productivity, is still needed. This is especially important in relation to the ongoing and rapid development of mining and large-scale wind farms within the Sámi reindeer husbandry ranges.

Acknowledgments We would like to give sincere thanks to Prof. Emiritus Öje Danell for valuable input in the work of this paper. We also thank three anonymous reviewers whose comments improved the manuscript. The work of Dr. Anna Skarin has been possible through financing from "Reindriftens utvecklings fond", Norwegian Research Council, Norway, within the project "Vindkraft i reinbetesland". 
Open Access This article is distributed under the terms of the Creative Commons Attribution License which permits any use, distribution, and reproduction in any medium, provided the original author(s) and the source are credited.

\section{References}

Aastrup P (2000) Responses of West Greenland caribou to the approach of humans on foot. Polar Res 19:83-90

Anttonen M, Kumpula J, Colpaert A (2011) Range selection by semidomesticated reindeer (Rangifer tarandus tarandus) in relation to infrastructure and human activity in the boreal forest environment, northern Finland. Arctic 64:1-14

Apps CD, McLellan BN, Kinley TA, Flaa JP (2001) Scale-dependent habitat selection by mountain Caribou, Columbia Mountains, British Columbia. J Wildl Manag 65:65-77

Bailey DW, Gross JE, Laca EA, Rittenhouse LR, Coughenour MB, Swift DM, Sims PL (1996) Mechanisms that result in large herbivore grazing distribution patterns. J Range Manag 49:386-400

Banfield AWF (1961) A revision of the reindeer and caribou, genus Rangifer. Bull Natl Mus Canada 177:1-137

Baskin LM (1986) Differences in the ecology and behaviour of reindeer populations in the USSR. Rangifer $6 \mathrm{Spec}$ Issue $1: 333-340$

Baskin L, Hjältén J (2001) Fright and flight behaviour of reindeer. Alces 37:435-445

Bejder L, Samuels A, Whitehead H, Finn H, Allen S (2009) Impact assessment research: use and misuse of habituation, sensitisation and tolerance in describing wildlife responses to anthropogenic stimuli. Mar Ecol Prog Ser 395:177-185. doi:10.3354/Meps07979

Benhamou S, Riotte-Lambert L (2012) Beyond the utilization distribution: identifying home range areas that are intensively exploited or repeatedly visited. Ecol Model 227:112-116. doi:10.1016/j.ecolmodel.2011.12.015

Bergerud A (1988) Caribou, wolves and man. Trends Ecol Evol 3:68-72. doi:10.1016/0169-5347(88)90019-5

Bergmo T (2011) Potential avoidance and barrier effects of a power line on range use and migration patterns of semi-domesticated reindeer (Rangifer tarandus tarandus). MSc thesis, Norwegian University of Life Sciences

Bjørklund I (2013) Domestication, reindeer husbandry and the development of sami pastoralism. Acta Boreal 30:174-189. doi:10.1080/08003831.2013.847676

Boulanger J, Poole KG, Gunn A, Wierzchowski J (2012) Estimating the zone of influence of industrial developments on wildlife: a migratory caribou Rangifer tarandus groenlandicus and diamond mine case study. Wildl Biol 18:164-179. doi:10.2981/11045

Cameron RD, Smith WT, White RG, Griffith B (2005) Central arctic caribou and petroleum development: distributional, nutritional, and reproductive implications. Arctic 58:1-9

Clutton-Brock J (2012) Animals as domesticates: a world view through history. The animal turn. Michigan State University Press, East Lansing

Colman JE, Eftestol S, Tsegaye D, Flydal K, Mysterud A (2012) Is a wind-power plant acting as a barrier for reindeer Rangifer tarandus tarandus movements? Wildl Biol 18:439-445. doi:10. 2981/11-116

Colman JE, Eftestol S, Tsegaye D, Flydal K, Mysterud A (2013) Summer distribution of semi-domesticated reindeer relative to a new wind-power plant. Euro J Wildl Res 59:359-370. doi:10. 1007/s10344-012-0682-7
Danell Ö (2005) The robustness of reindeer husbandry-need for a new approach to elucidate opportunities and sustainability of the reindeer industry in its socio-ecological context. Rangifer Rep 10:39-49

Degteva A, Nellemann C (2013) Nenets migration in the landscape: impacts of industrial development in Yamal peninsula, Russia. Pastor Res Policy Pract 3:15

Espmark Y (1964) Studies in dominance-subordination relationship in a group of semi-domesticated reindeer (Rangifer tarandus L.). Anim Behav 12:420-426

Flydal K, Eftestøl S, Reimers E, Colman J (2004) Effects of wind turbines on area use and behviour of semi-domesticated reindeer in enclosures. Rangifer 24:55-66

Flydal K, Korslund L, Reimers E, Johansen F, Colman JE (2009) Effects of power lines on area use and behaviour of semidomesticated reindeer in enclosures. Int $\mathrm{J}$ Ecol. doi:10.1155/ 2009/340953

Frid A, Dill L (2002) Human-caused disturbance stimuli as a form of predation risk. Conserv Ecol, Vol 6, p 11. http://www.consecol. org/vol16/iss11/art11

Goebel T, Waters MR, O'Rourke DH (2008) The late pleistocene dispersal of modern humans in the Americas. Science 319:1497-1502. doi:10.1126/Science.1153569

Hanson WC (1981) Caribou (Rangifer tarandus) encounters with Pipelines in Northern Alaska. Can Field Nat 95:57-62

Harrington FH (2003) Caribou, military jets and noise: the interplay of behavioural ecology and evolutionary psychology. Rangifer 23 Spec Issue 14:73-80

Helle T, Särkelä M (1993) The effect of outdoor recreation on range use by semi-domesticated reindeer. Scand J Forest Res 8:123-133

Helle T, Hallikainen V, Sarkela M, Haapalehto M, Niva A, Puoskari J (2012) Effects of a holiday resort on the distribution of semidomesticated reindeer. Ann Zool Fenn 49:23-35

Helskog K, Indrelid S (2011) Humans and reindeer. Quatern Int 238:1-3. doi:10.1016/j.quaint.2011.03.018

Hemmer H (1990) Domestication the decline of environmental appreciation (trans: Beckhaus N), 2nd edn. Cambridge University Press, Cambridge

Johnson DH (1980) The comparison of usage and availability measurements for evaluating resource preference. Ecology 6:65-71

Joly K, Nellemann C, Vistnes I (2006) A reevaluation of caribou distribution near an oilfield road on Alaska's North Slope. Wildl Soc Bull 34:866-869. doi:10.2193/0091-7648(2006)34[866: Arocdn]2.0.Co; 2

Kitti H, Gunslay N, Forbes B (2006) Defining the quality of reindeer pastures: the perspective of Sámi reindeer herders. In: Forbes BC, Bölter M, Müller-Wille L et al (eds) Reindeer management in Northernmost Europe, Ecological studies. Springer, Berlin, pp 141-165

Klein DR (1971) Reaction of reindeer to obstructions and disturbances. Science 173:393-398. doi:10.1126/Science.173.3995. 393

Knight RL, Cole DN (1995) Factors that influence wildlife responses to recreationists. In: Knight RL, Gutzwiller KJ (eds) Wildlife and recreationists: coexistence through management and research. Island Press, New York, pp 71-79

Kumpula J, Colpaert A, Anttonen M (2007) Does forest harvesting and linear infrastructure change the usability value of pastureland for semi-domesticated reindeer (Rangifer tarandus tarandus)? Ann Zool Fenn 44:161-178

Leblond M, Frair J, Fortin D, Dussault C, Ouellet JP, Courtois R (2011) Assessing the influence of resource covariates at multiple spatial scales: an application to forest-dwelling caribou faced 
with intensive human activity. Lands Ecol 26:1433-1446. doi:10.1007/S10980-011-9647-6

Leblond M, Dussault C, Ouellet JP (2013) Avoidance of roads by large herbivores and its relation to disturbance intensity. J Zool 289:32-40. doi:10.1111/j.1469-7998.2012.00959.x

Luell B, Strand O (2006) Monitoring effects of highway traffic on wild reindeer. On the road to stewardship. In: Irwin CL, Garett P, McDermott KP (eds) International conference on ecology and transportation. San Diego, California

Lundqvist H (2007) Ecological cost-benefit modelling of herbivore habitat quality degradation due to range fragmentation. Transact GIS 11:745-763. doi:10.1111/j.1467-9671.2007.01070.x

Mahoney SP, Schaefer JA (2002) Hydroelectric development and the disruption of migration in caribou. Biol Conserv 107(2):147-153

Maier JAK, Murphy SM, White RG, Smith MD (1998) Responses of caribou to overflights by low-altitude jet aircraft. J Wildl Manag 62:752-766

Manning AD, Lindenmayer DB, Nix HA (2004) Continua and Umwelt: novel perspectives on viewing landscapes. Oikos 104:621-628. doi:10.1111/J.0030-1299.2004.12813.X

Mayor SJ, Schaefer JA, Schneider DC, Mahoney SP (2009) The spatial structure of habitat selection: a caribou's-eye-view. Acta Oecol 35:253-260. doi:10.1016/J.Actao.2008.11.004

Nagy JA, Johnson DL, Larter NC et al (2011) Subpopulation structure of caribou (Rangifer tarandus L.) in arctic and subarctic Canada. Ecol Appl 21:2334-2348. doi:10.1890/10-1410.1

Nellemann C, Jordhoy P, Stoen O-G, Strand O (2000) Cumulative impacts of tourist resorts on wild reindeer (Rangifer tarandus tarandus) during winter. Arctic 53:9-17

Nellemann C, Vistnes I, Jordhoy P, Strand O (2001) Winter distribution of wild reindeer in relation to power lines, roads and resorts. Biol Conserv 101:351-360

Nellemann C, Vistnes I, Jordhoy P, Strand O, Newton A (2003) Progressive impact of piecemeal infrastructure development on wild reindeer. Biol Conserv 113:307-317

Nellemann C, Vistnes I, Jordhoy P, Stoen OG, Kaltenborn BP, Hanssen F, Helgesen R (2010) Effects of recreational cabins, trails and their removal for restoration of reindeer winter ranges. Restor Ecol 18:873-881. doi:10.1111/j.1526-100X. 2009.00517.x

Nieminen M (2013) Response distances of wild forest reindeer (Rangifer tarandus fennicus Lönnb.) and semi-domestic reindeer (R. t. tarandus L.) to direct provocation by a human on foot/ snowshoes. Rangifer 33:1-15

Oskal A, Turi JM, Mathiesen SD, Burgess P (eds) (2009) Ealát Reindeer Herders's voice: reindeer herding, traditional knowledge and adaptation to climate change and loss of grazing land. Association of World Reindeer Herders, International Centre for reindeer Husbandry, Sámi allaskuvla, Alta

Össbo Å, Lantto P (2011) Colonial tutelage and industrial colonialism. Reindeer husbandry and early 20th-century hydroelectric development in Sweden. Scand J Hist 36:324-348. doi:10.1080/ 03468755.2011.580077

Panzacchi M, Van Moorter B, Jordhoy P, Strand O (2012) Learning from the past to predict the future: using archaeological findings and GPS data to quantify reindeer sensitivity to anthropogenic disturbance in Norway. Lands Ecol. doi:10.1007/s10980-0129793-5

Pape R, Loeffler J (2012) Climate change, land use conflicts, predation and ecological degradation as challenges for reindeer husbandry in Northern Europe: what do we really know after half a century of research? Ambio 41:421-434. doi:10.1007/s13280012-0257-6

Polfus JL, Hebblewhite M, Heinemeyer K (2011) Identifying indirect habitat loss and avoidance of human infrastructure by northern mountain woodland caribou. Biol Conserv 144:2637-2646. doi:10.1016/j.biocon.2011.07.023

Price EO (1999) Behavioral development in animals undergoing domestication. Appl Anim Behav Sci 65:245-271

Reimers E, Colman JE (2006) Reindeer and caribou (Rangifer tarandus) response towards human activities. Rangifer 26:55-71

Reimers E, Svela S (2001) Vigilance behavior in wild and semidomestic reindeer in Norway. Alces 37:303-313

Reimers E, Loe LE, Eftestol S, Colman JE, Dahle B (2009) Effects of hunting on response behaviors of wild reindeer. J Wildl Manag 73:844-851. doi:10.2193/2008-133

Reimers E, Roed KH, Colman JE (2012) Persistence of vigilance and flight response behaviour in wild reindeer with varying domestic ancestry. J Evol Biol 25:1543-1554. doi:10.1111/J.1420-9101. 2012.02538.X

Rettie WJ, Messier F (2000) Hierarchical habitat selection by woodland caribou: its relationship to limiting factors. Ecography $23: 466-478$

Roed KH, Flagstad O, Nieminen M, Holand O, Dwyer MJ, Rov N, Vila C (2008) Genetic analyses reveal independent domestication origins of Eurasian reindeer. Proc R Soc B Biol Sci 275:1849-1855. doi:10.1098/Rspb.2008.0332

Senft RL, Coughenour MB, Bailey DW, Rittenhouse LR, Sala OE, Swift DM (1987) Large herbivore foraging and ecological hierarchies. Bioscience 37:789-799

Skarin A (2007) Habitat use by semi-domesticated reindeer, estimated with pellet-group counts. Rangifer 27:121-132

Skarin A, Danell Ö, Bergstrom R, Moen J (2004) Insect avoidance may override human disturbances in reindeer habitat selection. Rangifer 24:95-103

Skarin A, Danell Ö, Bergstrom R, Moen J (2008) Summer habitat preferences of GPS-collared reindeer Rangifer tarandus tarandus. Wildl Biol 14:1-15

Skarin A, Danell Ö, Bergstrom R, Moen J (2010) Reindeer movement patterns in alpine summer ranges. Polar Biol 33:1263-1275. doi:10.1007/s00300-010-0815-y

Skarin A, Nellemann C, Sandström P, Rönnegård L, Lundqvist H (2013) Renar och Vindkraft - Studie från anläggningen av två vindkraftparker i Malå sameby. Swedish Environmental Agency, Stockholm http://www.naturvardsverket.se/Documents/publika tioner6400/978-91-620-6564-5.pdf

Skjenneberg S, Slagsvold L (1968) Reindriften og dens naturgrunnlag. Scandinavian University Books-Universitetsforlaget, Oslo/ Bergen/Tromsø - translated to English: Skjenneberg S, Slagsvold L (1979) Reindeer Husbandry and its Ecological Principles (trans: Deehr TT). U.S. Department of the Interior Bureau of Indian Affairs, Juneau, Alaska

Tyler NJC, Turi JM, Sundset MA, Bull KS, Sara MN, Reinert E, Oskal N, Nellemann C, McCarthy JJ, Mathiesen SD, Martello ML, Magga OH, Hovelsrud GK, Hanssen-Bauer I, Eira NI, Eira IMG, Corell RW (2007) Saami reindeer pastoralism under climate change: applying a generalized framework for vulnerability studies to a sub-arctic social-ecological system. Global Environ Chang 17(2):191-206. doi:10.1016/J.Gloenvcha.2006. 06.001

UNEP (2001) Globio-global methodology for mapping human impacts on the biosphere. In: Nellemann C, Kullerud 1, Vistnes I, Forbes BC, Husby E, Kofinas GP, Kaltenborn BP et al (eds) Nairobi, Kenya. http://www.globio.info/downloads/218/globiore portlowres.pdf

Utsi M (1948) The reindeer-breeding methods of the Northern Lapps. Man 48:97-101

Vistnes II (2008) Impacts of human development and activity on reindeer and caribou habitat use. Dissertation, Norweigan University of Life Sciences 
Vistnes I, Nellemann C (2001) Avoidance of cabins, roads, and power lines by reindeer during calving. J Wildl Manag 65:915-925

Vistnes I, Nellemann C (2008) The matter of spatial and temporal scales: a review of reindeer and caribou response to human activity. Polar Biol 31:399-407

Vistnes I, Nellemann C, Jordhoy P, Strand O (2001) Wild reindeer: impacts of progressive infrastructure development on distribution and range use. Polar Biol 24:531-537

Vistnes I, Nellemann C, Jordhoy P, Strand O (2004) Effects of infrastructure on migration and range use of wild reindeer. J Wildl Manag 68:101-108

Vistnes II, Nellemann C, Jordhoy P, Stoen OG (2008) Summer distribution of wild reindeer in relation to human activity and insect stress. Polar Biol 31:1307-1317. doi:10.1007/s00300-0080468-2

Weir JN, Mahoney SP, McLaren B, Ferguson SH (2007) Effects of mine development on woodland caribou Rangifer tarandus distribution. Wildl Biol 13:66-74. doi:10.2981/0909-6396 (2007)13[66:Eomdow]2.0.Co;2
White RG (1983) Foraging patterns and their multiplier effects on productivity of northern ungulates. Oikos 40:377-384

White RG (1992) Nutrition in relation to season, lactation, and growth of north temperate deer. In: Brown RD (ed) The biology of deer. Springer, New York, pp 407-417

White RG, Bunnell FL, Gaare E, Skogland T, Hubert B (1981) Ungulates on arctic ranges. In: Bliss LC, Heal OW, Moore JJ (eds) Tundra ecosystems a comparative analysis. The international biology progressive, vol 25. Cambridge University Press, Cambridge, pp 397-483

Wiens JA (1973) Pattern and process in grassland bird communities. Ecol Monogr 43:237-270

Wilson RR, Gilbert-Norton L, Gese EM (2012) Beyond use versus availability: behaviour-explicit resource selection. Wildl Biol 18:424-430. doi:10.2981/12-044

Wolfe SA, Griffith B, Wolfe CAG (2000) Response of reindeer and caribou to human activities. Polar Res 19:63-73

Zhigunov PS (ed) (1968) Reindeer husbandry. Israel program for scientific translation Ltd, Jerusalem 